\title{
APESM statistics and summary of 2017-2018
}

\author{
Jamie Trapp ${ }^{1}$
}

Published online: 10 September 2019

๑) Australasian College of Physical Scientists and Engineers in Medicine 2019

It is of potential interest to readers of APESM to know some of the statistics and highlights of the journal in the past year, as has been published previously [1].

Table 1 shows summary statistics for both 2017 and 2018, as well as previously published statistics for 2014-2016 [1]. Consistent growth can be seen in the number of manuscripts received over several years, although the total number of articles published has only slightly increased, indicating an increasing rejection rate. All manuscripts received undergo a quality check, and many are found to be unsuitable or not ready for review; of these, many are returned to the authors for correction prior to review and many are rejected without review. The rate of rejection without review has remained fairly consistent at roughly $30-40 \%$.

In 2018 APESM published a special section on Advanced in artificial intelligence in biomedical image analysis, edited by Kelvin Wong and Jianxu Chen [2] which contained 4 articles [3-6], with a review article being published in the following issue [7].

The top 20 keywords of articles (source: Scopus) are given in Table 2. The topics of articles can roughly be sorted into groups describing medical physics studies (algorithms, radiation response, dosimetry, radiotherapy, dose-response relationship, diagnostic imaging, image processing), biomedical engineering [algorithm(s), signal processing, signal processing computer assisted], and clinical [Human(s), controlled study, male, female, adult, radiation response, procedures, clinical article].

\section{Awards}

Each year the Kenneth Clarke award is presented to the authors of the best article to have originated from Australasian authors from the previous year, as voted for by the editorial team including the editor, deputy editors, associate editors and Editorial Review Board members. In 2018 the award went to the authors of Predicting prostate tumour location from multiparametric MRI using Gaussian kernel support vector machines: a preliminary study [8]. In 2017 the award went to the authors of Initial experiments with gel-water: towards MRI-linac dosimetry and imaging [9]. The Springer citation award for 2018 (most cited article of those published in the years from 2013 to 2017) went to Mobile healthcare applications: system design review, critical issues and challenges [10].
Jamie Trapp

j.trapp@qut.edu.au

1 School of Chemistry, Physics, and Mechanical Engineering, Queensland University of Technology, Brisbane, Australia 
Table 1 Manuscript statistics of APESM 2014-2018

\begin{tabular}{llll}
\hline Year & $\begin{array}{l}\text { Number of MS } \\
\text { submitted }\end{array}$ & $\begin{array}{l}\text { Number of scientific } \\
\text { articles published }\end{array}$ & $\begin{array}{l}\text { Number of MS } \\
\text { rejected without } \\
\text { review }\end{array}$ \\
\hline 2014 & 211 & 68 & 85 \\
2015 & 289 & 69 & 101 \\
2016 & 297 & 84 & 119 \\
2017 & 304 & 87 & 133 \\
2018 & 460 & 83 & 184 \\
\hline
\end{tabular}

Table 2 Occurrences of keywords for 2017-2018 articles

Keywords (occurrence)

Article (169)

Human (169)

Humans (162)

Controlled study (65)

Algorithm (62)

Male (57)

Algorithms (56)

Female (50)

Adult (46)

Radiation response (39)

Dosimetry (37)

Radiotherapy (36)

Signal processing (36)

Procedures (35)

Dose-response relationship, radiation (34)

Signal processing, computer-assisted (33)

Physiology (32)

Clinical article (30)

Diagnostic imaging (27)

Computer simulation (25)

Image processing (25)

\section{References}

1. Caon M (2018) Operational statistics for the APESM (20142016). Australas Phys Eng Sci Med 40(3):487-489

2. Wong K, Chen J (2018) Special section: advances in artifical intelligence in biomedical image analysis. Australas Phys Eng Sci Med 41:1075

3. Bai B, Liu P-Z, Du Y-Z, Luo Y-M (2018) Automatic segmentation of cervical region in colposcopic images. Australas Phys Eng Sci Med 41(4):1077-1085

4. Zeng D, Peng J, Fong S, Qiu Y, Wong R (2018) Medical data mining in sentiment analysis based on optimized swarm search feature selection. Australas Phys Eng Sci Med 41(4):1087-1100

5. Fan Y, Liu P, Tang J, Luo Y, Du Y (2018) Fuzzy entropy based on differential evolution for breast gland segmentation. Australas Phys Eng Sci Med 41(4):1101-1114

6. Zhang P, Qiu Q, Zhou Y (2018) Reconstruction of continuous brachial artery pressure wave from continuous finger arterial pressure in humans. Australas Phys Eng Sci Med 41(4):1115-1125

7. Sun Y, Reynolds H, Parameswaran B, Wraith D, Finnegan M, Williams S, Haworth A (2019) Multiparametric MRI and radiomics in prostate cancer: a review. Australas Phys Eng Sci Med 42(1):3-25

8. Sun Y, Reynolds H, Wraith D, Williams S, Finnegan M, Mitchell C, Murphy D, Ebert M, Haworth A (2017) Predicting prostate tumour location from multiparametric MRI using Gaussian kernel support vector machines: a preliminary study. Australas Phys Eng Sci Med 40(1):39-49

9. Alnaghy SJ, Gargett M, Liney G, Petasecca M, Begg J, Espinoza A, Newall MK, Duncan M, Holloway L, Lerch M, Lazea M, Rosenfeld A, Metcalfe P (2016) Initial experiments with gelwater: towards MRI-linac dosimetry and imaging. Australas Phys Eng Sci Med 39:921-932

10. Baig MM, GholamHosseini H, Connolly MJ (2015) Mobile healthcare applications: system design review, critical issues and challenges. Australas Phys Eng Sci Med 38(1):23-38

Publisher's Note Springer Nature remains neutral with regard to jurisdictional claims in published maps and institutional affiliations. 